\title{
Cutaneous Notch Signaling in Health and Disease
}

\author{
Craig Nowell and Freddy Radtke \\ Swiss Institute for Experimental Cancer Research (ISREC), Ecole Polytechnique Federale \\ Lausanne (EPFL), Lausanne 1015, Switzerland \\ Correspondence: Freddy.Radtke@epfl.ch
}

The development and maintenance of the skin are dependent on myriad signaling pathways that regulate a variety of cellular processes. In cutaneous epithelial cells, the Notch cascade plays a central role in ensuring that proliferation and differentiation are coordinated appropriately, a function that it imparts during both ontogeny and homeostasis. Aberrations of the Notch signaling pathway result in severe abnormalities in the epidermis and its appendages and cause functional defects such as perturbed barrier function. In addition, impaired Notch signaling is associated with diseases of the skin such as atopy and cancer. The pathology associated with aberrant cutaneous Notch signaling reflects the complex mechanisms underpinning its function in this tissue and involves both cell-autonomous and nonautonomous mechanisms. This review summarizes our current knowledge of the role of Notch signaling in the skin during health and disease.

\begin{abstract}
$T^{\text {hew }}$ he Notch signaling pathway is an evolutionarily conserved cascade that regulates the development and homeostasis of a variety of tissues (Hansson et al. 2004; Wilson and Radtke 2006). Consistent with its central role in regulating these events, aberrant Notch signaling is often causative for a range of diseases including cancer (Radtke and Raj 2003; Koch and Radtke 2007). The cellular processes that it controls include, but are not restricted to, the maintenance and differentiation of stem cells, cell fate determination, and cell-cycle regulation (Wilson and Radtke 2006). Additional functions are being revealed as investigations continue, and it is clear that the role of Notch
\end{abstract}

signaling is highly complex and multifaceted. Furthermore, it frequently elicits disparate outcomes in different tissues, illustrating that the effects of Notch signaling are highly context dependent.

This review is focused on the role that Notch signaling plays in the epithelial cells of the interfollicular epidermis (IFE) and its appendages, such as the hair follicle (HF). An overview of the current understanding of the role of Notch signaling in cutaneous epithelial cells is provided with respect to both its physiological function and its influence on diseases of the skin, with a particular focus on its role during cutaneous carcinogenesis.

Editors: Anthony E. Oro and Fiona M. Watt

Additional Perspectives on The Skin and Its Diseases available at www.perspectivesinmedicine.org

Copyright (C) 2013 Cold Spring Harbor Laboratory Press; all rights reserved; doi: 10.1101/cshperspect.a017772

Cite this article as Cold Spring Harb Perspect Med 2013;3:a017772 


\section{NOTCH-MEDIATED SIGNAL TRANSDUCTION}

Notch signal transduction is initiated by ligation of Notch receptors with ligands expressed on neighboring cells. Mammals possess four Notch receptors (Notch1-4) and five ligands (Jagged1 and 2 and Delta-like 1, 3, and 4) (Radtke et al. 2004). The receptors are synthesized as single precursor proteins that are cleaved during transport to the cell surface, where they are expressed as heterodimers. Ligand-receptor interaction between two neighboring cells results in two successive proteolytic cleavages. The first is mediated by a metalloprotease of the ADAM family (TACE, tumor necrosis factor- $\alpha$-converting enzyme), which cleaves the receptor in the extracellular domain, close to the transmembrane domain. The released extracellular domain is then transendocytosed by the ligand-expressing cell. The second cleavage occurs within the transmembrane (TM) domain and is mediated by the $\gamma$-secretase activity of a multiprotein complex consisting of presenilin, nicastrin, APH1, and PEN2 (Fortini 2002). This final cleavage liberates the cytoplasmic domain of the Notch receptor (NICD), which subsequently translocates to the nucleus, where it binds to its downstream transcription factor CSL (CBF1 in humans, Suppressor of hairless in Drosophila, and LAG in Caenorhabditis elegans, also known as RBP-J in mice) and thereby activates transcription (Fig. 1). To date, only a few Notch target genes have been identified, some of which are dependent on Notch signaling in multiple tissues, whereas others are tissuespecific. The best known targets are members of the basic helix-loop-helix (bHLH) transcription factor family, Hairy enhancer of split (Hes), which function as transcriptional repressors and negatively regulate gene expression (Ishibashi 2004).

\section{SITES OF NOTCH ACTIVITY IN THE SKIN}

The site of Notch activity in the skin has been determined by analyzing the expression of Notch signaling components during development and homeostasis.
Studies in mice and in human tissue indicate that Notch receptors and ligands are distributed in spatially restricted expression patterns throughout the epidermis and its appendages.

In the IFE, Notch 1, 2, and 3 are expressed at the highest levels in the suprabasal cells of the spinous and granular layers, where cells are undergoing differentiation (Kopan and Weintraub 1993; Powell et al. 1998; Favier et al. 2000; Nickoloff et al. 2002; Thelu et al. 2002; Pan et al. 2004; Blanpain et al. 2006). Human IFE has also been shown to express Notch 4 (Nickoloff et al. 2002).

The ligands expressed in the IFE are Jagged1 and Jagged-2, which are expressed predominantly in the suprabasal layers, with limited expression in basal cells (Powell et al. 1998; Nickoloff et al. 2002; Thelu et al. 2002; Pan et al. 2004; Estrach et al. 2006). Delta-like 1 expression has been shown in fetal and adult human tissue, where it is found throughout the basal layer of the IFE (Lowell et al. 2000; Thelu et al. 2002), although the highest levels of expression are restricted to clusters thought to represent epidermal stem cells (Lowell et al. 2000). In mouse, Delta-like 1 expression was initially reported only in the mesenchymal cells of the embryonic skin (Powell et al. 1998; Favier et al. 2000), but more recently the use of a Delta-like 1 reporter strain has revealed a similar expression pattern to that observed in humans, with expression in clusters of cells in the basal layer (Fig. 2A) (Estrach et al. 2008).

In HFs, Notch 1, 2, and 3 are expressed in the matrix and pre-cortex of the follicle base and are also found in the more distal locations of the hair shaft and inner root sheath (Fig. 2B) (Kopan and Weintraub 1993; Powell et al. 1998; Favier et al. 2000; Pan et al. 2004). Jagged-1 and Jagged- 2 are the only ligands detected in the HFs and are expressed in the matrix and pre-cortex and also in the outer root sheath (Fig. 2B) (Powell et al. 1998; Favier et al. 2000; Estrach et al. 2006). As with the IFE, the locations of Notch receptor and ligand expression in the HF are restricted to areas where cells are undergoing both early and late stages of differentiation. 


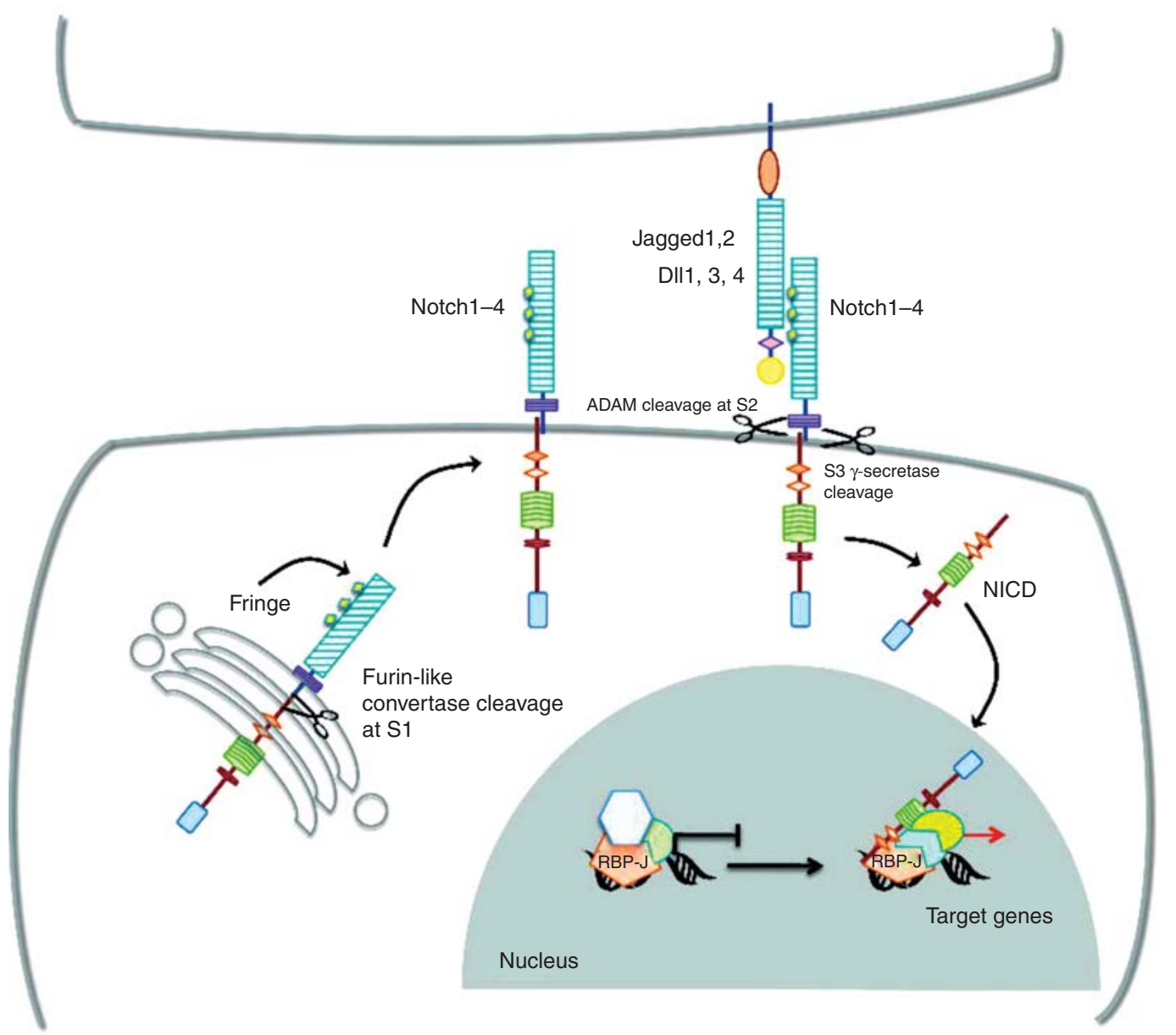

Figure 1. Notch signaling. Vertebrates have four Notch receptors (Notch1-Notch4, N1-N4) and five conventional ligands (Jagged1, Jaggged2, Delta-like1 [Dll1], Delta-like3 [Dll3], and Delta-like4 [Dll4]). Notch proteins are synthesized as single precursor proteins, which are cleaved in the Golgi by a Furin-like convertase at site S1. Cleavage at S1 generates two subunits held together noncovalently. EGF-like repeats present within the extracellular domain of the receptors are glycosylated by Fringe proteins in the Golgi before receptors are transported to the cell surface. Notch signaling is initiated by ligand-receptor interaction, which induces a second cleavage at site S2 (close to the transmembrane domain) mediated by ADAM-type metalloproteases, followed by a third cleavage at S3 within the transmembrane domain mediated by the $\gamma$-secretase activity of a multiprotein complex containing presenilins. This last proteolytic cleavage liberates the cytoplasmic domain of Notch receptors (NICD), which translocate to the nucleus and bind to the transcription factor RBP-J, converting it from a transcriptional repressor into a transcriptional activator by recruiting coactivators to induce target gene expression.

The expression of Notch signaling components that are indicative of receptor activation, such as NICD and the Hes/Hey family of transcriptional repressors, largely confirms the sites of Notch activity inferred from the patterns of receptor/ligand expression (Lin and Kopan
2003; Okuyama et al. 2004; Pan et al. 2004; Vauclair et al. 2005; Blanpain et al. 2006; Estrach et al. 2006; Moriyama et al. 2006; Ambler and Watt 2007; Lee et al. 2007). More recent studies have used reporter systems to determine sites of Notch activity. Transgenic systems in which 


\author{
C. Nowell and F. Radtke
}

\title{
A
}
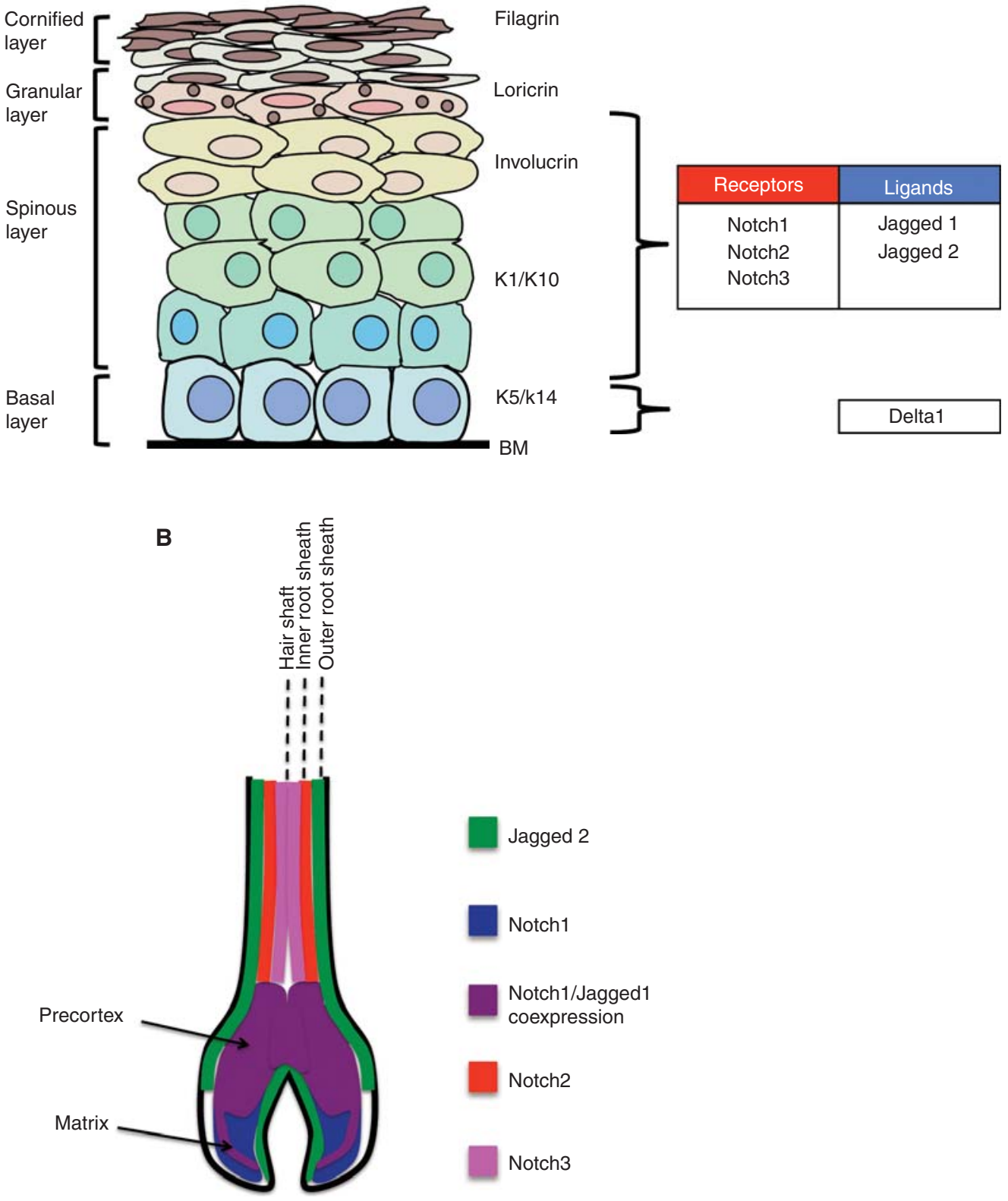

Figure 2. Expression of Notch signaling components in the skin. (A) Schematic representation of the murine skin showing the expression pattern of components of the Notch signaling pathway. The epidermis is a stratified squamous epithelium that is composed of multiple cell layers. The basal cell layer localizes to the basement membrane (BM) and consists mostly of TA cells intermingled with a few stem cells. The basal cell layer gives rise first to the spinous layer followed by the granular layer and then the cornified layer. The expression of Notch receptors and ligands is indicated. $(B)$ Schematic depiction of Notch receptor and ligand expression in the hair follicle. Notch 1 is expressed in the matrix and pre-cortex, Notch2 in the upper portion of the pre-cortex and inner root sheath, and Notch3 in the hair shaft. Jagged 1 is expressed in a small portion of the matrix and in the pre-cortex. Jagged 2 is expressed in the cells adjacent to the dermal papilla and in the outer root sheath. (Image based on data from Watt et al. 2008.) 
a GFP reporter gene is placed under the control of RBP-J response elements or the endogenous Hes1 promoter reveal GFP expression in suprabasal cells of the interfollicular epidermis and in the matrix cells of the anagen hair follicle (Estrach et al. 2006; Moriyama et al. 2006).

Collectively, these studies indicate that Notch activity is associated with differentiation in both the IFE and the growing hair follicle.

\section{FUNCTIONAL ANALYSIS OF CUTANEOUS NOTCH SIGNALING}

The physiological role of cutaneous Notch signaling has been determined by the analysis of genetically modified mice carrying loss- and gain-of-function mutations in components of the Notch pathway.

Skin-specific deletion of RBP-J in mice results in complete ablation of cutaneous Notch signaling and causes severe abnormalities of both the IFE and HFs. Ablation during development results in loss of the spinous and granular layers of the IFE, causing severe barrier defects resulting in death shortly after birth (Blanpain et al. 2006). In these mice, the basal layer of the epidermis is present, although it is maintained in a nonproliferative state. Specification and patterning of HFs in RBP-J mutants occur normally, but differentiation of the matrix cells, pre-cortex, and inner root sheath is impaired (Pan et al. 2004; Blanpain et al. 2006). In a separate model, ablation of RBP-J in the skin is induced in a mosaic fashion that prevents neonatal lethality and thus allows postnatal evaluation of RBP-J-deficient skin (Yamamoto et al. 2003). In these mice, the IFE also displays loss of the differentiated layers, but the basal layer is maintained. However, in contrast to the phenotype observed in neonates, basal progenitor cells in the postnatal skin show severe hyperproliferation. Postnatal RBP-J-deficient HFs adopt an epidermal fate and degenerate into large cysts, resulting in complete hair loss. Similar results are obtained when Presenelin 1 and 2 are deleted in the developing hair follicles, resulting in loss of $\gamma$-secretase activity and therefore abrogation of Notch signaling (Pan et al. 2004). Postnatal deletion of RBP-J in the IFE and HFs recapitulates many of the abnormalities observed upon ablation during development, including perturbed proliferation and differentiation of the IFE and degeneration of HFs into epidermal cysts (Dumortier et al. 2010). This shows that Notch activity is required throughout the lifetime of the mammalian skin.

The studies described above indicate that a key function of cutaneous Notch signaling is the promotion and maintenance of the differentiated state. In keeping with this, overexpression of N1ICD in the basal layer of the IFE promotes the early stages of differentiation with a concomitant loss of basal progenitor cells, causing severe blistering (Blanpain et al. 2006; Estrach et al. 2006). In vitro experiments also show that Notch induces growth arrest in keratinocytes as well as promoting the early stages of differentiation (Rangarajan et al. 2001; Okuyama et al. 2004). Thus, Notch1 negatively regulates the proliferation of cutaneous epithelial progenitor cells and is essential for their subsequent differentiation.

The receptors responsible for mediating Notch signaling in cutaneous epithelial cells have been identified using mice carrying conditional mutations in Notch1-4. In these experiments, deletion of Notch1 alone, either during development or postnatally, results in phenotypic abnormalities in both the IFE and HF (Nicolas et al. 2003; Vauclair et al. 2005). In contrast, ablation of Notch2, 3, or 4 does not cause any overt phenotype in the skin (Krebs et al. 2000, 2003; Pan et al. 2004). However, Notch1 ablation does not fully recapitulate the abnormalities observed in RBP-J mutants. For example, although the Notch1-deficient IFE does display abnormal basal cell proliferation and aberrant late-stage differentiation, the spinous and granular layers are present (Nicolas et al. 2003; Vauclair et al. 2005). In addition, only a proportion of the HF degenerate into epidermal cysts after Notch1 deletion, and the cysts that do form are generally much smaller (Vauclair et al. 2005). These findings suggest that the loss of Notch1 is partially compensated for by Notch2, 3, and/or 4. Consistent with this, combined deletion of Notch 1 and Notch2 in the 
skin fully recapitulates the phenotype observed in RBP-J mutants (Dumortier et al. 2010), thus confirming that Notch2 also mediates canonical Notch signaling in the skin.

Of the ligands expressed in skin, Jagged 1 appears to be the primary inducer of Notch signaling, because conditional Jagged 1 mutants show HF degeneration and hyperproliferation of the IFE (Estrach et al. 2006). In contrast, ablation of Jagged 2 in the skin causes no overt abnormalities (Watt et al. 2008). Loss of Dll1 expression causes defects in the proliferation and differentiation of the IFE but has no effect on the HFs and is consistent with the spatial localization of Dll1 exclusively in the basal layer of the IFE (Estrach et al. 2008). Interestingly, Dll1 appears to play a critical role in regulating the maintenance of stem cells in the IFE. In human skin, the highest levels of Dlll expression are found in distinct clusters of cells in the basal layer that are thought to represent epidermal stem cells (Lowell et al. 2000). In vitro studies using human epidermal keratinocytes indicate that Dll1 maintains stem cells in an undifferentiated state by cis inhibition of Notch signaling while promoting the differentiation of cells adjacent to the stem-cell clusters (Lowell et al. 2000; Estrach et al. 2007). In this way, Dll1 mediates a mode of Notch signaling reminiscent of lateral inhibition in the Drosophilasensory organ precursor (Heitzler and Simpson 1993). In addition, Dll1 is critical for the formation of cohesive clusters of stem cells, a function that is Notch independent (Lowell et al. 2000; Estrach et al. 2007). It is therefore likely that Dll1 ensures that the stem-cell compartment remains restricted to its specific niche. Consistent with this, single-cell gene expression profiling reveals a striking correlation between the expression of Dll1 and genes associated with stem-cell-niche interactions (Tan et al. 2013).

\section{MOLECULAR MECHANISMS AND CROSS TALK WITH OTHER SIGNALING PATHWAYS}

The molecular mechanisms by which Notch signaling regulates cutaneous development and homeostasis are complex and multifaceted and involve interactions with a variety of other signaling pathways (Fig. 3).

One mechanism by which canonical Notch signaling mediates its effects is via the induction of $\mathrm{CDKN} 1 \mathrm{~A} / \mathrm{p} 21$, which negatively regulates cell-cycle progression and induces growth ar-

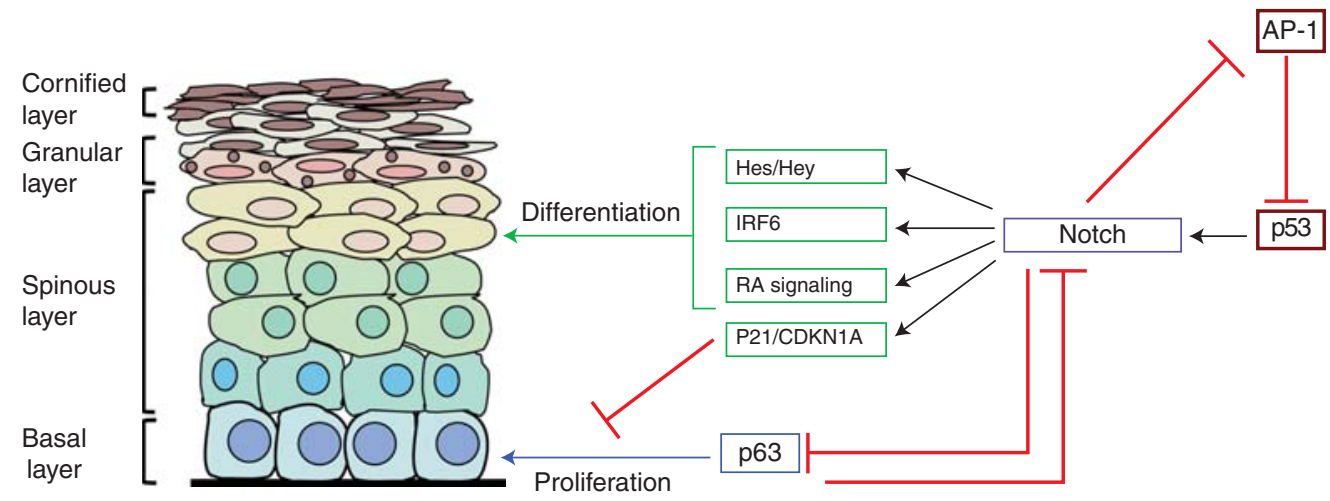

Figure 3. Molecular mechanisms of Notch-mediated epidermal homeostasis. A schematic diagram depicting the intersecting pathways and downstream effectors during Notch-induced differentiation. Notch expression and/ or signaling in epidermal keratinocytes are promoted by p53 and antagonized by AP-1, which represses p53 expression. Notch also represses AP-1 activity, suggesting that the Notch and AP-1 pathways are mutually antagonistic. Notch signaling subsequently promotes cell-cycle arrest of progenitor cells in the basal layer by repressing p63 and by inducing the expression of the cell-cycle inhibitor CDKN1a/p21. Differentiation is promoted by the induction of factors including IRF6 and the Hes/Hey family of transcriptional repressors. Notch also promotes RA signaling by inducing the expression of retinol-binding proteins such as CRABP2, FABP5, and CRBP-1. Activation of the RA pathway promotes the differentiation of the epidermal epithelium. 
rest. In vitro studies on mouse epidermal keratinocytes indicate that the induction of CDKN1A/p21 by Notch is RBP-J dependent (Rangarajan et al. 2001). There is also evidence that CDKN1A/p21 is regulated by Notch in human keratinocytes, although the magnitude of the increase is smaller, and the effect on growth is more prolonged (Nguyen et al. 2006).

The canonical Notch target Hes1 accounts for some of the prodifferentiation functions of Notch signaling in the epidermis, because intermediate stages of maturation are perturbed in Hes1 mutant mice (Moriyama et al. 2008). However, large elements of the Notch mutant phenotype are independent of the Hes/Hey transcriptional repressors, thus pointing to alternative mechanisms of action.

In this respect, Notch signaling seems to affect the function of a variety of other signaltransduction cascades that play clear roles in development and homeostasis of the skin. Perhaps one of the most significant is p63, which belongs to the p53 family of transcription factors and exists as several isoforms that show distinct expression patterns (Yang et al. 2002). The $\Delta \mathrm{Np} 63 \alpha$ isoform is generally associated with epithelial stem/progenitor cells in stratified epithelial tissues (McKeon 2004) and plays an important functional role in the proliferation of progenitors during the process of stratification (Senoo et al. 2007; Keyes et al. 2011; Shalom-Feuerstein et al. 2011). p63 displays a reciprocal expression pattern to sites of Notch activation (Senoo et al. 2007). Consistent with this, Notch signaling represses p63 expression during differentiation, and overexpression of p63 in human epidermal keratinocytes counteracts the prodifferentiation function of Notch (Nguyen et al. 2006). The mechanism by which Notch opposes p63 expression involves the regulation of interferon response factors (IRFs). In human and mouse epidermal keratinocytes, Notch-mediated repression of p63 is concomitant with the repression of IRF3/7, both of which prevent p63 down-regulation when overexpressed (Nguyen et al. 2006). Conversely, a recent study has shown that another IRF family member, IRF6, is a primary Notch target gene in human epidermal keratinocytes and is required for their differentiation in response to Notch activation (Restivo et al. 2011). Thus, Notch signaling may differentially regulate specific IRFs to suppress p63 and to directly promote differentiation (Fig. 3).

Notch also positively regulates vitamin A/ retinoic acid (RA) signaling in the skin and in other stratified epithelia (Vauclair et al. 2007; Collins and Watt 2008). RA signaling is active in the IFE and HF, where it performs a prodifferentiation function (Saitou et al. 1995). Notch signaling leads to increased expression of retinol-binding proteins such as CRBP1, CRABP2, and FABP5, which facilitate the binding of RA to nuclear receptors and thus play an important role in mediating RA signal transduction (Collins and Watt 2008). The positive regulation of the RA pathway by Notch is opposed, at least in the HFs, by the Wnt signaling cascade, which represses the expression of CRABP2 and FABP5, suggesting that Notch and Wnt signaling act antagonistically in the HF via the regulation of the RA pathway. Conversely, there is evidence supporting a cooperative relationship between Notch and Wnt signaling in the HF, because Jagged1, which promotes Notch-mediated differentiation of the inner root sheath, is a $\beta$-catenin target gene (Estrach et al. 2006). These disparities likely reflect the complex interplay that exists between the Notch and Wnt pathways, which are highly complex and context dependent.

There is an increasing body of data indicating that Notch signaling and AP-1 signaling interact significantly in the skin to regulate epidermal homeostasis and function. AP-1 is a transcriptional complex consisting of heterodimers composed of members of the jun, fos, and Fra family of proteins. The AP-1 factors become activated in response to stress via a variety of extracellular stimuli, where they regulate target gene expression and control processes such as proliferation, apoptosis, differentiation, and inflammation (Eferl and Wagner 2003). One of the key regulators of AP-1 activity is the EGFR pathway, which activates c-jun via ERK-mediated phosphorylation. Interestingly, the effects of increased EGFR activity in the skin mimic to some degree the Notch mutant 
phenotype, because high levels of EGFR signaling promote proliferation and impair differentiation of the IFE and promote an epidermal fate in HFs (Kolev et al. 2008). Conversely, inhibition of EGFR signaling leads to increased epidermal differentiation of keratinocytes via up-regulation of Notch1 and its downstream targets. It has subsequently been shown that c-jun mediates the effects of EGFR by downregulating p53, a transcription factor that directly induces Notchl transcription (Kolev et al. 2008). A similar mechanism has been shown with respect to c-fos, which also represses p53, although in this example, p53 was shown to activate Notch signaling by inducing ADAM17/ TACE-mediated receptor cleavage (Fig. 3) (Guinea-Viniegra et al. 2012). Each of these studies positions AP-1 upstream of Notch in regulating epidermal differentiation. However, there is evidence that Notch and AP-1 show reciprocal antagonism, because genetic ablation of ADAM17 / TACE results in high levels of AP-1 activity that induce many of the abnormalities associated with loss of Notch signaling in the skin (Murthy et al. 2012). The extent to which AP-1 is directly regulated by Notch remains to be determined, because the observed effects may be a secondary consequence of impaired differentiation and function. Nonetheless, it is clear that there is a link between Notch and AP-1 in the skin and that disruption of their interaction has severe consequences for cutaneous development and homeostasis.

\section{NOTCH AND THE REGULATION OF CUTANEOUS INFLAMMATION}

An emerging role of cutaneous Notch signaling is the regulation of inflammation. Ablation of cutaneous Notch signaling in mice, by either RBP-J deletion or combined loss of Notch1 and Notch2, results in the overexpression of proinflammatory cytokines causing a chronic inflammatory disorder resembling atopic dermatitis (AD) (Demehri et al. 2008; Dumortier et al. 2010). A link between Notch signaling and human $\mathrm{AD}$ is provided by the demonstration that patients with atopic dermatitis show reduced expression of Notch receptors in the epi- dermis (Dumortier et al. 2010). Furthermore, the proinflammatory cytokine that displays the highest elevation upon ablation of Notch signaling in mice is thymic stromal lymphopoietin (TSLP), a proinflammatory cytokine with pleiotropic effects that is causative for human allergic disorders such as atopic dermatitis and asthma (Ziegler and Artis 2010; Jariwala et al. 2011).

Additional evidence showing a link between the Notch pathway and inflammation is provided by the demonstration that ectopic Notch expression in basal epidermal cells results in serious abnormalities in the underlying dermis, characterized by an inflammatory infiltrate consisting of T cells (Ambler and Watt 2010). Thus, inflammation appears to be extremely sensitive to aberrations in epidermal Notch signaling, either with respect to signal strength or spatial localization.

The induction of aberrant inflammatory responses in the absence of Notch activity is likely to have consequences with respect to the phenotypic abnormalities observed in epithelial cells of the IFE and HF. Chronic inflammation leads to the expression and secretion of a variety of factors that can activate critical pathways involved in proliferation and differentiation. In light of this, it is interesting to note that basal hyperproliferation of RBP-J-deficient IFE occurs only during postnatal life (Yamamoto et al. 2003; Blanpain et al. 2006), when a chronic inflammatory microenvironment has been established.

The mechanism by which Notch signaling is able to regulate inflammation remains unclear, although it is noteworthy that many of the signaling cascades that show a mutually repressive relationship with Notch play a positive regulatory role with respect to cutaneous inflammation. For example, AP-1 can induce the expression of proinflammatory cytokines including TSLP, suggesting that Notch can prevent/attenuate inflammation via its repressive activity toward AP-1 (Murthy et al. 2012). EGFR signaling, which also shows an antagonistic relationship with Notch, induces the epidermal expression of the proinflammatory cytokine GM-CSF via the activation of c-jun (Mascia et al. 2010), providing further evidence for the operation of 
a Notch-AP-1 axis in the regulation of cutaneous inflammation.

\section{NOTCH SIGNALING AND CUTANEOUS CARCINOGENESIS}

The ability to conditionally ablate Notch signaling in mouse epidermis and its appendages has enabled a detailed analysis of its role during the development of nonmelanoma skin cancer. Nonmelanoma skin cancers are among the most common human malignancies in northern Europe and the United States and are generally classified into three types depending on their histopathological appearance and the genetic lesions underlying their development (Arwert et al. 2012). The most frequent is basal cell carcinoma (BCC), which usually shows histopathological hallmarks suggestive of follicular differentiation and is dependent on activation of the Sonic hedgehog pathway (Hahn et al. 1996; Oro et al. 1997). The second most common is squamous cell carcinoma (SCC), which shows morphological characteristics of IFE and is dependent on Ras pathway activation (Owens and Watt 2003; Ridky and Khavari 2004). Although not as prevalent as BCC, SCC is generally more aggressive and, unlike BCC, can metastasize. Finally, Wnt/ $\beta$-catenin activation can induce tumors from progenitor cells in the HF and sebaceous glands (Gat et al. 1998; Chan et al. 1999; Takeda et al. 2006; Lo Celso et al. 2008; Arwert et al. 2012).

In each of these tumors, aberrant regulation of stem/progenitor cell proliferation underlies the initial carcinogenesis (Owens and Watt 2003; Arwert et al. 2012). However, studies using mouse models suggest that the precise cell of origin can vary and instead indicate that the primary determining factor is the genetic lesion driving tumorigenesis (Arwert et al. 2012).

\section{NOTCH1 FUNCTIONS AS A TUMOR SUPPRESSOR IN BCC AND SCC}

Evidence linking Notch signaling to the development of nonmelanoma skin cancer has been provided predominantly by the analysis of Notch1-deficient skin in mice. Ablation of
Notch1 in the IFE and HFs results in the spontaneous development of BCC over time, in addition to the physiological abnormalities described previously (Nicolas et al. 2003). Consistent with a BCC classification, Notch1-deficient tumors show increased expression of the Hedgehog targets Gli1, Gli2, and Patched, indicating increased activity of the Hedgehog signaling cascade (Nicolas et al. 2003). Thus, loss of Notch1 in the skin results in increased susceptibility to BCC, indicating that Notch 1 functions as a tumor suppressor in this context.

Skin-specific ablation of Notch1 in mice also renders these mutants highly susceptible to two-stage chemical carcinogenesis (Nicolas et al. 2003; Demehri et al. 2009), which induces the development of SCC by promoting the expansion of epidermal stem cells carrying H-ras mutations (Arwert et al. 2012). These lesions also develop spontaneously over time in Notch1-deficient skin, showing that in mice, Notch1 also acts as a tumor suppressor with respect to SCC. A recent study has subsequently identified loss-of-function mutations in Notch1 in patient samples of cutaneous SCC, supporting the hypothesis that Notch signaling counteracts cutaneous SCC development (Agrawal et al. 2011; Stransky et al. 2011; Wang et al. 2011).

The role of Notch1 in the development of HF-derived tumors is less clear. Although deletion of Notch1 in the HF results in perturbed differentiation, the abnormal follicles do not form the benign tumors associated with overactivation of the Wnt $/ \beta$-catenin pathway. However, complete loss of Notch signaling can lead to follicular tumor development in specific contexts (Di Piazza et al. 2012), suggesting that follicular epithelial cells are still subject to Notchmediated tumor suppression but to lower levels of sensitivity.

\section{CELL-INTRINSIC MECHANISMS OF NOTCH1-MEDIATED TUMOR SUPPRESSION}

The mechanisms underlying the tumor-suppressor role of Notch1 remain to be fully elucidated. However, the fact that nonmelanoma skin cancers are associated with aberrant regulation 
of stem-cell activity suggests that it is partially due to its intrinsic prodifferentiation effects.

In support of this, the protumorigenic role of pathways such as EGFR and AP-1 are associated with their capacity to impair Notch1-induced differentiation, whereas the tumor-suppressive function of $\mathrm{p} 53$ seems to rely in part on its ability to induce Notch1 expression and therefore promote maturation. For example, the ability of AP-1 to promote SCC development is dependent on its ability to suppress p53 and thereby inhibit Notch1-induced differentiation (Kolev et al. 2008; Guinea-Viniegra et al. 2012). Conversely, p53 prevents tumor development via Notch1-dependent suppression of the ROCK1/2 and MRCK $\alpha$ kinases, resulting in loss of adhesion to the basement membrane and subsequent differentiation (Lefort et al. 2007).

Notch1 is also likely to mediate tumor suppression by inducing cell-cycle arrest in epidermal stem/progenitor cells. As described above, Notch1 inhibits $\Delta \mathrm{Np} 63 \alpha$ expression, which promotes proliferation of epithelial stem cells and can exert oncogenic effects in the skin (Keyes et al. 2011). It is also possible that CDKN1A/ p21, which is induced by Notch1 and induces cell-cycle arrest, is an important downstream effector during tumor suppression.

Notch1 may also inhibit tumorigenesis by suppressing the Wnt/ $\beta$-catenin pathway in the IFE (Nicolas et al. 2003), which is required for the maintenance of SCC cancer stem cells (Malanchi et al. 2008). However, the evidence supporting this is purely correlative, and no direct mechanistic link between Notch and Wnt/ $\beta$-catenin in the IFE has been shown.

\section{NONAUTONOMOUS MECHANISMS OF NOTCH-MEDIATED TUMOR SUPPRESSION}

An increasingly important theme emerging in cancer biology is how malignant cells of the tumor interact with nontransformed cells of the host. A large body of evidence now indicates that malignancies develop in the context of a protumorigenic stroma, which includes hematopoietic cells, fibroblasts, and vascular endothelial cells (Erez et al. 2010; Pietras and Ostman
2010; Beck et al. 2011; Hanahan and Weinberg 2011). Importantly, these constituents have been shown to play a critical role during all stages of carcinogenesis, including initiation, malignant progression, and the promotion of metastasis. In light of this, the demonstration that loss of epidermal Notch signaling induces considerable aberrations in the underlying dermis suggests that the nonautonomous consequences of Notch ablation in the skin are likely to be significant with respect to carcinogenesis.

In this respect, there is some evidence that loss of Notch signaling in the epidermis can indeed promote tumorigenesis by inducing a protumorigenic stroma. Utilization of the two-stage chemical carcinogenesis protocol on mice that undergo mosaic deletion of Notch 1 in the skin results in tumor development from both Notch1-deficient and Notch1 wild-type epithelial cells (Demehri et al. 2009). In this system, tumor development remains associated with Notch1 deficiency in the IFE, but the carcinogenic effect is not dependent on a cell-intrinsic mechanism. Although this does not directly show that the Notch1-deficient epidermis promotes a protumorigenic microenvironment, it does nonetheless support the hypothesis that nonautonomous mechanisms are active in promoting skin cancer upon loss of Notch1 signaling.

In a more recent study, it has been shown that deletion of RBP-J in the dermis results in the development of chronic inflammation, fibrosis, and SCC ( $\mathrm{Hu}$ et al. 2012). Because in this system no predisposing oncogenic mutations are induced in the IFE, tumor development occurs in response to the changes in the underlying dermis following Notch-signaling ablation, thus confirming that the induction of a protumorigenic microenvironment is sufficient to initiate carcinogenesis.

The nonautonomous effects of Notch signaling during cutaneous carcinogenesis may be linked to its role in regulating cutaneous inflammation. Depending on its qualitative aspects, inflammation can be either anti- or protumorigenic and has been shown to be an essential constituent of the protumorigenic stroma in many epithelial malignancies (Balkwill et al. 
2005; Mantovani et al. 2008; Solinas et al. 2010; Balkwill and Mantovani 2012), including those of the skin (Andreu et al. 2010; Arwert et al. 2010). Furthermore, the development of cutaneous malignancies that are associated with loss of Notch signaling can be induced by wounding, which elicits both stem-cell activation and inflammation (Sibilia et al. 2000; Kasper et al. 2011; Arwert et al. 2012). This is consistent with the hypothesis that Notch signaling may prevent skin cancer in part by regulating inflammatory responses.

\section{NOTCH SIGNAL STRENGTH INFLUENCES CUTANEOUS CARCINOGENESIS BY MODULATING INFLAMMATION}

The tumor-suppressor function of Notch signaling in the skin has been studied largely with respect to the role of Notch1. An important question, therefore, is how does complete loss of canonical Notch signaling affect cutaneous carcinogenesis? Two recent studies have addressed this issue by analyzing tumor development in both RBP-J-deficient mice and Notch1:Notch2 compound mutants (Demehri et al. 2012; Di Piazza et al. 2012). As described above, in addition to the abnormalities in the IFE and HFs, skin-specific ablation of either RBP-J or Notch receptors 1 and 2 results in a chronic inflammatory phenotype mediated by the proinflammatory cytokine TSLP (Demehri et al. 2008; Dumortier et al. 2010). Intriguingly, the epidermis in these mice is also resistant to both spontaneous tumor development and chemically induced carcinogenesis, in contrast to the consequences of Notch 1 deletion alone. This protective effect is mediated by TSLP, because abrogation of signaling via the TSLP receptor results in severe tumor burden in Notchdeficient skin, manifested by spontaneous development of invasive HF tumors and exophytic tumors resembling SCC. It was subsequently shown that TSLP elicits an antitumor immune response dependent on both CD4 and CD8 T cells, and in this way invokes an inflammatory response that prevents carcinogenesis. Importantly, this effect is not restricted to Notch-deficient tumors, because cutaneous malignancies carrying wild-type alleles of Notch receptors are also sensitive to TSLP-mediated tumor suppression (Demehri et al. 2012; Di Piazza et al. 2012).

Tumor development in Notch $^{-/-}$: Notch $2^{-/-}$and RBP-J ${ }^{-/-}$skin occurs rapidly in the absence of TSLP-mediated immune responses, suggesting that cutaneous epithelial cells deficient in canonical Notch signaling are intrinsically predisposed to malignancy. However, in keeping with previous studies, tumor development is also highly dependent on protumorigenic inflammation (Andreu et al. 2010; Arwert et al. 2010, 2012). In this respect, Notchdeficient epithelial cells elicit a qualitatively distinct type of inflammation, characterized by high numbers of myeloid cells that promote tumor growth by augmenting Wnt signaling (Di Piazza et al. 2012). Thus, Notch-deficient epithelial cells escape immune surveillance in the absence of TSLP-mediated immune responses and invoke protumorigenic inflammation that favors their expansion.

These findings indicate that the outcome of Notch-signaling ablation with respect to cutaneous carcinogenesis is highly dependent on the degree of signaling impairment. This, in turn, is a function of the inflammatory response elicited in the skin following Notch ablation. Thus, in the complete absence of Notch signaling, the inflammatory response is skewed toward antitumor immunity owing to the high levels of TSLP secreted from the epidermis. Importantly, this immune response is of sufficient strength to prevent the outgrowth of cells that may have intrinsic tumorigenic potential (Fig. 4). Conversely, the reduction in signal strength induced by loss of Notch1 alone results in intermediate levels of TSLP secretion (Demehri et al. 2008), thus inducing a permissive environment for the outgrowth of malignant cells (Fig. 4).

Collectively, these recent findings show that the tumor-suppressor function of cutaneous Notch signaling involves the coordination of both autonomous and nonautonomous cellular responses. The extent to which this regulation is direct remains to be determined. Nonetheless, it is clear that Notch plays a central role in controlling many of the processes that contribute to the development of skin cancer. 

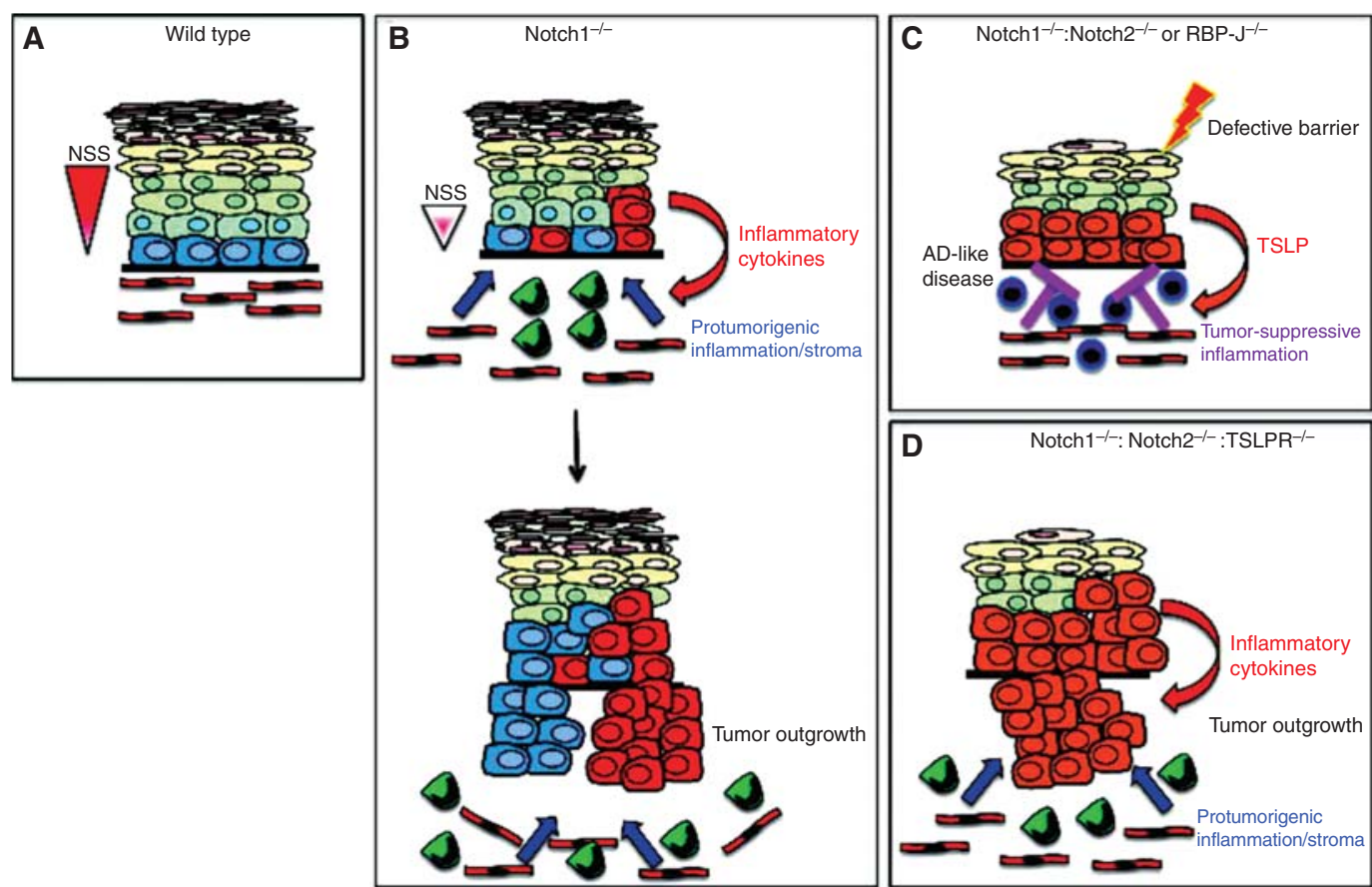

Notch $1^{-/-}$basal progenitor

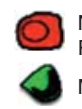

Notch $1^{-1-}:$ Notch2 $2^{-/-}$or RBP-J $J^{-1-}$ basal progenitor

Myeloid cell

Figure 4. A model of how aberrant Notch signaling in the IFE influences carcinogenesis by regulating inflammation. (A) Depiction of wild-type epidermis in which normal levels of Notch signaling (red triangle to the left of diagram) ensure the correct balance between proliferation and differentiation. Fibroblasts constitute a significant proportion of the underlying dermis and provide support for epidermal stem/progenitor cells. $(B)$ Partial reduction of Notch signal strength by ablation of Notch1 results in perturbed epidermal differentiation and the secretion of proinflammatory cytokines. This leads to the infiltration of hematopoietic cells, including cells of the myeloid lineage, into the underlying dermis and the formation of a protumorigenic stroma, which promotes tumor development from Notch1 ${ }^{-/-}$and wild-type epidermal cells. $(C)$ Complete ablation of epidermal Notch signaling, by either compound deletion of Notch1 and Notch2 or ablation of RBP-J, results in extremely high levels of TSLP secretion and the subsequent development of an atopic-dermatitis (AD)-like disease. Elevated TSLP expression may occur by direct regulation of TSLP by Notch or may be a consequence of loss of barrier function. In addition to inducing $\mathrm{AD}$, high levels of TSLP prevent tumor development from the IFE and its appendages by inducing T-cell-mediated antitumor immunity. (D) Abrogation of TSLP-mediated immune responses by genetic ablation of the TSLPR results in rapid tumor development from cutaneous epithelial cells. Tumor growth remains dependent on protumorigenic inflammation, which is induced by the Notch-deficient IFE. NSS, Notch signal strength.

\section{CONCLUDING REMARKS}

Notch signaling plays a pivotal role in maintaining the homeostasis of cutaneous epithelial cells. It is now clear that this function is mediated by both autonomous and nonautonomous mechanisms, a finding that has important implications for understanding the role that aber- rant Notch signaling plays in diseases of the skin. In particular, further investigation of the link between Notch, inflammation, and cancer is likely to yield significant advancements in our understanding of how cutaneous epithelial malignancies, and perhaps other epithelial cancers, are initiated and maintained. A more in-depth knowledge of the biology underlying these pa- 
thologies will ultimately lead to the development of more efficacious therapeutic strategies.

\section{ACKNOWLEDGMENTS}

This work is supported in part by the Swiss National Science Foundation, the Swiss Cancer League, the Marie Curie Foundation, EuroSyStem, and OptiStem.

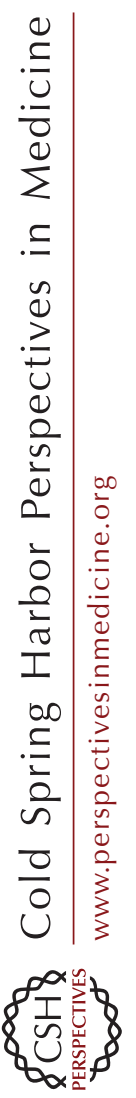

\section{REFERENCES}

Agrawal N, Frederick MJ, Pickering CR, Bettegowda C, Chang K, Li RJ, Fakhry C, Xie TX, Zhang J, Wang J, et al. 2011. Exome sequencing of head and neck squamous cell carcinoma reveals inactivating mutations in NOTCH1. Science 333: 1154-1157.

Ambler CA, Watt FM. 2007. Expression of Notch pathway genes in mammalian epidermis and modulation by ß-catenin. Dev Dyn 236: 1595-1601.

Ambler CA, Watt FM. 2010. Adult epidermal Notch activity induces dermal accumulation of $\mathrm{T}$ cells and neural crest derivatives through upregulation of jagged 1. Development 137: 3569-3579.

Andreu P, Johansson M, Affara NI, Pucci F, Tan T, Junankar S, Korets L, Lam J, Tawfik D, DeNardo DG, et al. 2010. FcR $\gamma$ activation regulates inflammation-associated squamous carcinogenesis. Cancer Cell 17: 121-134.

Arwert EN, Lal R, Quist S, Rosewell I, van Rooijen N, Watt FM. 2010. Tumor formation initiated by nondividing epidermal cells via an inflammatory infiltrate. Proc Natl Acad Sci 107: 19903-19908.

Arwert EN, Hoste E, Watt FM. 2012. Epithelial stem cells, wound healing and cancer. Nat Rev Cancer 12: 170-180.

Balkwill FR, Mantovani A. 2012. Cancer-related inflammation: Common themes and therapeutic opportunities. Semin Cancer Biol 22: 33-40.

Balkwill F, Charles KA, Mantovani A. 2005. Smoldering and polarized inflammation in the initiation and promotion of malignant disease. Cancer Cell 7: 211-217.

Beck B, Driessens G, Goossens S, Youssef KK, Kuchnio A, Caauwe A, Sotiropoulou PA, Loges S, Lapouge G, Candi A, et al. 2011. A vascular niche and a VEGF-Nrp1 loop regulate the initiation and stemness of skin tumours. Nature 478: 399-403.

Blanpain C, Lowry WE, Pasolli HA, Fuchs E. 2006. Canonical Notch signaling functions as a commitment switch in the epidermal lineage. Genes Dev 20: 3022-3035.

Chan EF, Gat U, McNiff JM, Fuchs E. 1999. A common human skin tumour is caused by activating mutations in $\beta$-catenin. Nat Genet 21: 410-413.

Collins CA, Watt FM. 2008. Dynamic regulation of retinoicacid-binding proteins in developing, adult and neoplastic skin reveals roles for $\beta$-catenin and Notch signalling. Dev Biol 324: 55-67.

Demehri S, Liu Z, Lee J, Lin MH, Crosby SD, Roberts CJ, Grigsby PW, Miner JH, Farr AG, Kopan R. 2008. Notchdeficient skin induces a lethal systemic B-lymphoprolif- erative disorder by secreting TSLP, a sentinel for epidermal integrity. PLoS Biol 6: e123.

Demehri S, Turkoz A, Kopan R. 2009. Epidermal Notch1 loss promotes skin tumorigenesis by impacting the stromal microenvironment. Cancer Cell 16: 55-66.

Demehri S, Turkoz A, Manivasagam S, Yockey LJ, Turkoz M, Kopan R. 2012. Elevated epidermal thymic stromal lymphopoietin levels establish an antitumor environment in the skin. Cancer Cell 22: 494-505.

Di Piazza M, Nowell CS, Koch U, Durham AD, Radtke F. 2012. Loss of cutaneous TSLP-dependent immune responses skews the balance of inflammation from tumor protective to tumor promoting. Cancer Cell 22: 479-493.

Dumortier A, Durham AD, Di Piazza M, Vauclair S, Koch U, Ferrand G, Ferrero I, Demehri S, Song LL, Farr AG, et al. 2010. Atopic dermatitis-like disease and associated lethal myeloproliferative disorder arise from loss of Notch signaling in the murine skin. PLoS ONE 5: e9258.

Eferl R, Wagner EF. 2003. AP-1: A double-edged sword in tumorigenesis. Nat Rev Cancer 3: 859-868.

Erez N, Truitt M, Olson P, Arron ST, Hanahan D. 2010. Cancer-associated fibroblasts are activated in incipient neoplasia to orchestrate tumor-promoting inflammation in an NF-кB-dependent manner. Cancer Cell 17: $135-$ 147.

Estrach S, Ambler CA, Lo Celso C, Hozumi K, Watt FM. 2006. Jagged 1 is a $\beta$-catenin target gene required for ectopic hair follicle formation in adult epidermis. Development 133: 4427-4438.

Estrach S, Legg J, Watt FM. 2007. Syntenin mediates Delta1induced cohesiveness of epidermal stem cells in culture. J Cell Sci 120: 2944-2952.

Estrach S, Cordes R, Hozumi K, Gossler A, Watt FM. 2008. Role of the Notch ligand Deltal in embryonic and adult mouse epidermis. J Invest Dermatol 128: 825-832.

Favier B, Fliniaux I, Thelu J, Viallet JP, Demarchez M, Jahoda CA, Dhouailly D. 2000. Localisation of members of the Notch system and the differentiation of vibrissa hair follicles: Receptors, ligands, and fringe modulators. Dev Dyn 218: 426-437.

Fortini ME. 2002. $\gamma$-Secretase-mediated proteolysis in cellsurface-receptor signalling. Nat Rev Mol Cell Biol 3: 673684.

Gat U, DasGupta R, Degenstein L, Fuchs E. 1998. De Novo hair follicle morphogenesis and hair tumors in mice expressing a truncated $\beta$-catenin in skin. Cell 95: 605-614.

Guinea-Viniegra J, Zenz R, Scheuch H, Jimenez M, Bakiri L, Petzelbauer P, Wagner EF. 2012. Differentiation-induced skin cancer suppression by FOS, p53, and TACE/ ADAM17. J Clin Invest 122: 2898-2910.

Hahn H, Wicking C, Zaphiropoulous PG, Gailani MR, Shanley S, Chidambaram A, Vorechovsky I, Holmberg E, Unden AB, Gillies S, et al. 1996. Mutations of the human homolog of Drosophila patchedin the nevoid basal cell carcinoma syndrome. Cell 85: 841-851.

Hanahan D, Weinberg RA. 2011. Hallmarks of cancer: The next generation. Cell 144: 646-674.

Hansson EM, Lendahl U, Chapman G. 2004. Notch signaling in development and disease. Semin Cancer Biol 14: $320-328$. 
Heitzler P, Simpson P. 1993. Altered epidermal growth factor-like sequences provide evidence for a role of Notch as a receptor in cell fate decisions. Development 117: 1113 1123

Hu B, Castillo E, Harewood L, Ostano P, Reymond A, Dummer R, Raffoul W, Hoetzenecker W, Hofbauer GF, Dotto GP. 2012. Multifocal epithelial tumors and field cancerization from loss of mesenchymal CSL signaling. Cell 149: 1207-1220.

Ishibashi M. 2004. Molecular mechanisms for morphogenesis of the central nervous system in mammals. Anat $S c i$ Int 79: 226-234.

Jariwala SP, Abrams E, Benson A, Fodeman J, Zheng T. 2011. The role of thymic stromal lymphopoietin in the immunopathogenesis of atopic dermatitis. Clin Exp Allergy 41: $1515-1520$.

Kasper M, Jaks V, Are A, Bergstrom A, Schwager A, Svard J Teglund S, Barker N, Toftgard R. 2011. Wounding enhances epidermal tumorigenesis by recruiting hair follicle keratinocytes. Proc Natl Acad Sci 108: 4099-4104.

Keyes WM, Pecoraro M, Aranda V, Vernersson-Lindahl E, Li W, Vogel H, Guo X, Garcia EL, Michurina TV, Enikolopov G, et al. 2011. $\Delta$ Np63 $\alpha$ is an oncogene that targets chromatin remodeler Lsh to drive skin stem cell proliferation and tumorigenesis. Cell Stem Cell 8: 164-176.

Koch U, Radtke F. 2007. Notch and cancer: A double-edged sword. Cell Mol Life Sci 64: 2746-2762.

Kolev V, Mandinova A, Guinea-Viniegra J, Hu B, Lefort K, Lambertini C, Neel V, Dummer R, Wagner EF, Dotto GP. 2008. EGFR signalling as a negative regulator of Notch 1 gene transcription and function in proliferating keratinocytes and cancer. Nat Cell Biol 10: 902-911.

Kopan R, Weintraub H. 1993. Mouse Notch: Expression in hair follicles correlates with cell fate determination. J Cell Biol 121: 631-641.

Krebs LT, Xue Y, Norton CR, Shutter JR, Maguire M, Sundberg JP, Gallahan D, Closson V, Kitajewski J, Callahan R, et al. 2000. Notch signaling is essential for vascular morphogenesis in mice. Genes Dev 14: 1343-1352.

Krebs LT, Xue Y, Norton CR, Sundberg JP, Beatus P, Lendahl U, Joutel A, Gridley T. 2003. Characterization of Notch3deficient mice: Normal embryonic development and absence of genetic interactions with a Notch1 mutation. Genesis 37: 139-143.

Lee J, Basak JM, Demehri S, Kopan R. 2007. Bi-compartmental communication contributes to the opposite proliferative behavior of Notch1-deficient hair follicle and epidermal keratinocytes. Development 134: 2795-2806.

Lefort K, Mandinova A, Ostano P, Kolev V, Calpini V, Kolfschoten I, Devgan V, Lieb J, Raffoul W, Hohl D, et al. 2007. Notch1 is a p53 target gene involved in human keratinocyte tumor suppression through negative regulation of ROCK1/2 and MRCK $\alpha$ kinases. Genes Dev 21: $562-577$.

Lin MH, Kopan R. 2003. Long-range, nonautonomous effects of activated Notchl on tissue homeostasis in the nail. Dev Biol 263: 343-359.

Lo Celso C, Berta MA, Braun KM, Frye M, Lyle S, Zouboulis CC, Watt FM. 2008. Characterization of bipotential epidermal progenitors derived from human sebaceous gland: Contrasting roles of c-Myc and $\beta$-catenin. Stem Cells 26: $1241-1252$.
Lowell S, Jones P, Le Roux I, Dunne J, Watt FM. 2000. Stimulation of human epidermal differentiation by DeltaNotch signalling at the boundaries of stem-cell clusters. Curr Biol 10: 491-500.

Malanchi I, Peinado H, Kassen D, Hussenet T, Metzger D, Chambon P, Huber M, Hohl D, Cano A, Birchmeier W, et al. 2008. Cutaneous cancer stem cell maintenance is dependent on $\beta$-catenin signalling. Nature 452: 650653.

Mantovani A, Allavena P, Sica A, Balkwill F. 2008. Cancerrelated inflammation. Nature 454: 436-444.

Mascia F, Cataisson C, Lee TC, Threadgill D, Mariani V, Amerio P, Chandrasekhara C, Souto Adeva G, Girolomoni G, Yuspa SH, et al. 2010. EGFR regulates the expression of keratinocyte-derived granulocyte/macrophage colony-stimulating factor in vitro and in vivo. $J$ Invest Dermatol 130: 682-693.

McKeon F. 2004. p63 and the epithelial stem cell: More than status quo? Genes Dev 18: 465-469.

Moriyama M, Osawa M, Mak SS, Ohtsuka T, Yamamoto N, Han H, Delmas V, Kageyama R, Beermann F, Larue L, et al. 2006. Notch signaling via Hes1 transcription factor maintains survival of melanoblasts and melanocyte stem cells. J Cell Biol 173: 333-339.

Moriyama M, Durham AD, Moriyama $\mathrm{H}$, Hasegawa $\mathrm{K}$, Nishikawa S, Radtke F, Osawa M. 2008. Multiple roles of Notch signaling in the regulation of epidermal development. Dev Cell 14: 594-604.

Murthy A, Shao YW, Narala SR, Molyneux SD, ZunigaPflucker JC, Khokha R. 2012. Notch activation by the metalloproteinase ADAM17 regulates myeloproliferation and atopic barrier immunity by suppressing epithelial cytokine synthesis. Immunity 36: 105-119.

Nguyen BC, Lefort K, Mandinova A, Antonini D, Devgan V, Della Gatta G, Koster MI, Zhang Z, Wang J, Tommasi di Vignano A, et al. 2006. Cross-regulation between Notch and p63 in keratinocyte commitment to differentiation. Genes Dev 20: 1028-1042.

Nickoloff BJ, Qin JZ, Chaturvedi V, Denning MF, Bonish B, Miele L. 2002. Jagged-1-mediated activation of Notch signaling induces complete maturation of human keratinocytes through NF-кB and PPAR $\gamma$. Cell Death Differ 9: $842-855$.

Nicolas M, Wolfer A, Raj K, Kummer JA, Mill P, van Noort M, Hui CC, Clevers H, Dotto GP, Radtke F. 2003. Notch1 functions as a tumor suppressor in mouse skin. Nat Genet 33: $416-421$.

Okuyama R, Nguyen BC, Talora C, Ogawa E, Tommasi di Vignano A, Lioumi M, Chiorino G, Tagami H, Woo M Dotto GP. 2004. High commitment of embryonic keratinocytes to terminal differentiation through a Notch1caspase 3 regulatory mechanism. Dev Cell 6: 551-562.

Oro AE, Higgins KM, Hu Z, Bonifas JM, Epstein EH Jr, Scott MP. 1997. Basal cell carcinomas in mice overexpressing Sonic hedgehog. Science 276: 817-821.

Owens DM, Watt FM. 2003. Contribution of stem cells and differentiated cells to epidermal tumours. Nat Rev Cancer 3: 444-451.

Pan Y, Lin MH, Tian X, Cheng HT, Gridley T, Shen J, Kopan R. 2004. $\gamma$-Secretase functions through Notch signaling to maintain skin appendages but is not required for their 
patterning or initial morphogenesis. Dev Cell 7: 731743.

Pietras K, Ostman A. 2010. Hallmarks of cancer: Interactions with the tumor stroma. Exp Cell Res 316: $1324-$ 1331.

Powell BC, Passmore EA, Nesci A, Dunn SM. 1998. The Notch signalling pathway in hair growth. Mech Dev 78: 189-192.

Radtke F, Raj K. 2003. The role of Notch in tumorigenesis: Oncogene or tumour suppressor? Nat Rev Cancer 3: 756-767.

Radtke F, Wilson A, Mancini SJ, MacDonald HR. 2004. Notch regulation of lymphocyte development and function. Nat Immunol 5: 247-253.

Rangarajan A, Talora C, Okuyama R, Nicolas M, Mammucari C, Oh H, Aster JC, Krishna S, Metzger D, Chambon P, et al. 2001. Notch signaling is a direct determinant of keratinocyte growth arrest and entry into differentiation. EMBO J 20: 3427-3436.

Restivo G, Nguyen BC, Dziunycz P, Ristorcelli E, Ryan RJ Ozuysal OY, Di Piazza M, Radtke F, Dixon MJ, Hofbauer GF, et al. 2011. IRF6 is a mediator of Notch pro-differentiation and tumour suppressive function in keratinocytes. EMBO J 30: 4571-4585.

Ridky TW, Khavari PA. 2004. Pathways sufficient to induce epidermal carcinogenesis. Cell Cycle 3: 621-624.

Saitou M, Sugai S, Tanaka T, Shimouchi K, Fuchs E, Narumiya S, Kakizuka A. 1995. Inhibition of skin development by targeted expression of a dominant-negative retinoic acid receptor. Nature 374: 159-162.

Senoo M, Pinto F, Crum CP, McKeon F. 2007. p63 is essential for the proliferative potential of stem cells in stratified epithelia. Cell 129: 523-536.

Shalom-Feuerstein R, Lena AM, Zhou H, De La Forest Divonne S, Van Bokhoven H, Candi E, Melino G, Aberdam D. 2011. $\Delta$ Np63 is an ectodermal gatekeeper of epidermal morphogenesis. Cell Death Differ 18: 887-896.

Sibilia M, Fleischmann A, Behrens A, Stingl L, Carroll J, Watt FM, Schlessinger J, Wagner EF. 2000. The EGF receptor provides an essential survival signal for SOS-dependent skin tumor development. Cell 102: 211-220.

Solinas G, Marchesi F, Garlanda C, Mantovani A, Allavena P. 2010. Inflammation-mediated promotion of invasion and metastasis. Cancer Metastasis Rev 29: 243-248.
Stransky N, Egloff AM, Tward AD, Kostic AD, Cibulskis K, Sivachenko A, Kryukov GV, Lawrence MS, Sougnez C, McKenna A, et al. 2011. The mutational landscape of head and neck squamous cell carcinoma. Science 333: $1157-1160$.

Takeda H, Lyle S, Lazar AJ, Zouboulis CC, Smyth I, Watt FM. 2006. Human sebaceous tumors harbor inactivating mutations in LEF1. Nat Med 12: 395-397.

Tan DW, Jensen KB, Trotter MW, Connelly JT, Broad S, Watt FM. 2013. Single-cell gene expression profiling reveals functional heterogeneity of undifferentiated human epidermal cells. Development 140: 1433-1444.

Thelu J, Rossio P, Favier B. 2002. Notch signalling is linked to epidermal cell differentiation level in basal cell carcinoma, psoriasis and wound healing. BMC Dermatol 2: 7.

Vauclair S, Nicolas M, Barrandon Y, Radtke F. 2005. Notch1 is essential for postnatal hair follicle development and homeostasis. Dev Biol 284: 184-193.

Vauclair S, Majo F, Durham AD, Ghyselinck NB, Barrandon Y, Radtke F. 2007. Corneal epithelial cell fate is maintained during repair by Notch1 signaling via the regulation of vitamin A metabolism. Dev Cell 13: 242-253.

Wang NJ, Sanborn Z, Arnett KL, Bayston LJ, Liao W, Proby CM, Leigh IM, Collisson EA, Gordon PB, Jakkula L, et al. 2011. Loss-of-function mutations in Notch receptors in cutaneous and lung squamous cell carcinoma. Proc Natl Acad Sci 108: 17761-17766.

Watt FM, Estrach S, Ambler CA. 2008. Epidermal Notch signalling: Differentiation, cancer and adhesion. Curr Opin Cell Biol 20: 171-179.

Wilson A, Radtke F. 2006. Multiple functions of Notch signaling in self-renewing organs and cancer. FEBS Lett 580: 2860-2868.

Yamamoto N, Tanigaki K, Han H, Hiai H, Honjo T. 2003. Notch/RBP-J signaling regulates epidermis/hair fate determination of hair follicular stem cells. Curr Biol 13: 333-338.

Yang A, Kaghad M, Caput D, McKeon F. 2002. On the shoulders of giants: p63, p73 and the rise of p53. Trends Genet 18: 90-95.

Ziegler SF, Artis D. 2010. Sensing the outside world: TSLP regulates barrier immunity. Nat Immunol 11: 289-293. 


\section{$\&_{\mathrm{CSH}}^{\infty} \&$ Cold Spring Harbor

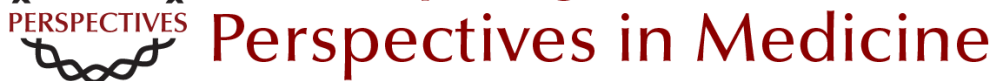

\section{Cutaneous Notch Signaling in Health and Disease}

Craig Nowell and Freddy Radtke

Cold Spring Harb Perspect Med 2013; doi: 10.1101/cshperspect.a017772

Subject Collection The Skin and Its Diseases

Melanoma: Clinical Features and Genomic Insights

Elena B. Hawryluk and Hensin Tsao

Wound Healing and Skin Regeneration

Makoto Takeo, Wendy Lee and Mayumi Ito

The Dermal Papilla: An Instructive Niche for

Epithelial Stem and Progenitor Cells in

Development and Regeneration of the Hair Follicle Bruce A. Morgan

Immunology and Skin in Health and Disease Jillian M. Richmond and John E. Harris

Desmosomes: Regulators of Cellular Signaling and Adhesion in Epidermal Health and Disease Jodi L. Johnson, Nicole A. Najor and Kathleen J. Green

Markers of Epidermal Stem Cell Subpopulations in Adult Mammalian Skin Kai Kretzschmar and Fiona M. Watt

Psoriasis Paola Di Meglio, Federica Villanova and Frank O. Nestle

Cell Therapy in Dermatology Gabriela Petrof, Alya Abdul-Wahab and John A. McGrath
Modeling Cutaneous Squamous Carcinoma

Development in the Mouse

Phillips Y. Huang and Allan Balmain

Natural and Sun-Induced Aging of Human Skin Laure Rittié and Gary J. Fisher

Advanced Treatment for Basal Cell Carcinomas Scott X. Atwood, Ramon J. Whitson and Anthony E. Oro

Epidermal Polarity Genes in Health and Disease Frederik Tellkamp, Susanne Vorhagen and Carien M. Niessen

Induced Pluripotent Stem Cells in Dermatology:

Potentials, Advances, and Limitations Ganna Bilousova and Dennis R. Roop

The Genetics of Human Skin Disease Gina M. DeStefano and Angela M. Christiano

p53/p63/p73 in the Epidermis in Health and Disease

Vladimir A. Botchkarev and Elsa R. Flores

Diversification and Specialization of Touch

Receptors in Skin

David M. Owens and Ellen A. Lumpkin

For additional articles in this collection, see http://perspectivesinmedicine.cshlp.org/cgi/collection/ 